\title{
Management of Hypotension in Preterm Infants (The HIP Trial): A Randomised Controlled Trial of Hypotension Management in Extremely Low Gestational Age Newborns
}

\author{
E.M. Dempsey ${ }^{\text {a }}$ K.J. Barrington ${ }^{\text {e }}$ N. Marlow ${ }^{\text {g }}$ C.P. O'Donnell ${ }^{b}$ J. Miletin ${ }^{c}$

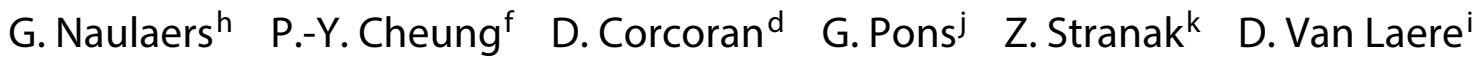 \\ on behalf of the HIP Consortium
}

\begin{abstract}
a Department of Paediatrics and Child Health, Neonatal Intensive Care Unit, University College Cork, Wilton, and
${ }^{b}$ National Maternity Hospital, ' Coombe Women and Infants University Hospital Dublin, and d Rotunda Hospital, Dublin, Ireland; ${ }^{\mathrm{C} C e n t r e ~ H o s p i t a l i e r ~ U n i v e r s i t a i r e ~ S a i n t e-J u s t i n e, ~ M o n t r e a l, ~ Q u e . ~ a n d ~}{ }^{\mathrm{f}}$ University of Alberta, Edmonton, Alta.,

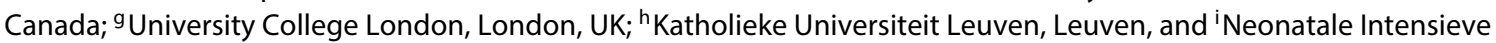
Zorgen, UZA, Edegem, Belgium; 'National de la Santé et de la Recherche Medicale, Cochin-Saint Vincent de Paul Hospital, Paris, France; ${ }^{k}$ Institute for the Care of Mother and Child, Prague Third Faculty of Medicine, Charles University, Prague, Czech Republic
\end{abstract}

\section{Key Words}

Survey - Hypotension - Diagnosis · Treatment .

Extremely low gestational age $\cdot$ Newborn

\begin{abstract}
Background: Extremely preterm babies (delivered at $<28$ completed weeks of gestation) are frequently diagnosed with hypotension and treated with inotropic and pressor drugs in the immediate postnatal period. Dopamine is the most commonly used first-line drug. Babies who are treated for hypotension more frequently sustain brain injury, have long-term disability or die compared to those who are not. Despite the widespread use of drugs to treat hypotension in such infants, evidence for efficacy is lacking, and the effect of these agents on long-term outcomes is unknown. $\mathbf{H y}$ pothesis: In extremely preterm babies, restricting the use of dopamine when mean blood pressure (BP) values fall below a nominal threshold and using clinical criteria to determine escalation of support ('restricted' approach) will result in im-
\end{abstract}

proved neonatal and longer-term developmental outcomes. Research Plan: In an international multi-centre randomised trial, 830 infants born at $<28$ weeks of gestation, and within $72 \mathrm{~h}$ of birth, will be allocated to 1 of 2 alternative treatment options (dopamine vs. restricted approach) to determine the better strategy for the management of $\mathrm{BP}$, using a conventional threshold to commence treatment. The first co-primary outcome of survival without brain injury will be determined at 36 weeks' postmenstrual age and the second coprimary outcome (survival without neurodevelopmental disability) will be assessed at 2 years of age, corrected for prematurity. Discussion: It is essential that appropriately designed trials be performed to define the most appropriate management strategies for managing low BP in extremely preterm babies.

(c) 2014 S. Karger AG, Basel

HIP Collaborators: Dr. Brendan Murphy, Prof. Cornelius Anthony Ryan, Prof. Geraldine Boylan, Prof. Naomi McCallion, Dr. Afif EL-Khuffash, Dr. Liesbeth Thewissen, Dr. Jana Semberová, Patrick Chevarier.

\begin{tabular}{ll}
\hline KARGER & $\begin{array}{l}\text { ( ) 2014 S. Karger AG, Basel } \\
\text { 1661-7800/14/1054-0275 } \$ 39.50 / 0 \quad \text { Karger }\end{array}$ \\
$\begin{array}{l}\text { E-Mail karger@karger.com } \\
\text { www.karger.com/neo }\end{array}$ & $\begin{array}{l}\text { This is an Open Access article licensed under the terms of the } \\
\text { Creative Commons Attribution-NonCommercial 3.0 Un- } \\
\text { ported license (CC BY-NC) (www.karger.com/OA-license), } \\
\text { applicable to the online version of the article only. Distribu- } \\
\text { tion permitted for non-commercial purposes only. }\end{array}$
\end{tabular}

Eugene Dempsey

Neonatal Intensive Care Unit

Department of Paediatrics and Child Health

University College Cork, Cork (Ireland)

E-Mail gene.dempsey@hse.ie 


\section{Introduction}

\section{Current Practice, Clinical Uncertainty}

Hypotension - low mean blood pressure (BP) - is commonly diagnosed and treated in very preterm infants, but clinical practice varies widely $[1,2]$. While hypotension is statistically associated with adverse short- and long-term outcomes, a systematic review of the literature was unable to find clear criteria to define hypotension [3]. The evidence base to support management of these infants is limited and predominantly includes studies that measured short-term physiological outcomes.

For example, the Cochrane Collaboration review of early volume expansion [4] could find no controlled studies evaluating volume expansion in hypotensive preterm infants compared to no volume. The two small controlled trials comparing crystalloid versus colloid for hypotensive preterm infants $(n=163)$ reported a few short-term clinical outcomes, including death, but only 1 reported common neonatal clinical outcomes (bronchopulmonary dysplasia or necrotising enterocolitis). Similarly, a Cochrane review of dopamine versus dobutamine for hypotension [5] included 5 small trials (total $n=243$ ), but only 3 reported mortality and only 2 reported intraventricular haemorrhage. None reported long-term outcomes. The other common therapy for hypotension is corticosteroid administration; however, a Cochrane review [6] found no studies with long-term follow-up for any of the comparisons (steroids vs. no treatment for primary treatment, treatment in refractory cases, or in comparison with inotropes). Although there was some evidence of efficacy in improving BP, no evidence of improvements in clinical outcomes was found.

Many preterm infants who are treated for hypotension have no biochemical or clinical signs of poor perfusion. These infants may have normal systemic blood flow, low systemic vascular resistance and adequate tissue oxygen delivery [7-10]. Rather than pharmacologic treatment, careful observation of such infants without intervention (an approach previously termed 'permissive hypotension') may well be appropriate [11].

Interventions to treat hypotension in preterm infants may be unhelpful or even harmful. Analysis of a large neonatal database (Canadian Neonatal Network) demonstrated that treatment of hypotension was associated with an increase in serious brain injury [12]. This remained true even after mean BP was included in the regression model, suggesting that it may be the treatment of hypotension, rather than the presence of hypotension, which is harmful. The most common approach to treatment is to give one or more fluid boluses followed by dopamine. However, observational data have shown an association of fluid bolus administration with intracranial bleeding [13]. In animal models, correction of hypotension by rapid volume infusion can result in intraventricular haemorrhage, a complication which is associated with increased rates of death and neurosensory impairment in preterm human infants. Fluctuations in BP following commencement of inotropes are well recognised and could also trigger intraventricular haemorrhage. Furthermore, dopamine, the most commonly used inotrope, has effects on many physiologic functions, including the pituitary gland, leading to secondary hypothyroidism, a known risk factor for poor long-term neurodevelopmental outcome in the preterm infant [14]. In addition, dopamine elevates BP in the newborn predominantly by causing vasoconstriction, which may be associated with a reduction in systemic perfusion $[15,16]$.

There is no consensus on threshold definitions for hypotension in preterm infants. Many clinicians rely on absolute mean $\mathrm{BP}$ values alone to guide intervention. BP reference ranges are often based on birth weight, gestational age (GA) and postnatal age criteria [17-22]. These statistically determined values vary considerably as they are based on observations of BP made in small cohorts of infants, the majority of whom were born before the widespread implementation of important perinatal interventions (e.g. antenatal glucocorticoid therapy) which are known to improve outcome and reduce the incidence of intraventricular haemorrhage in preterm infants [23]. The Joint Working Group of the British Association of Perinatal Medicine has recommended that the mean arterial $\mathrm{BP}(\mathrm{mm} \mathrm{Hg})$ should be maintained above the GA (weeks) (e.g. an infant born at 25 weeks of gestation should have a mean BP $>25 \mathrm{~mm} \mathrm{Hg}$ ) [24]. Despite little published evidence to support this 'rule', it remains the most commonly used criterion to define intervention and it has been used in a number of recent randomised therapeutic intervention trials where it was the sole entry criterion [25]. In preterm infants, however, there is a poor relationship between this and the incidence of intraventricular haemorrhage [26]. In a separate study, the Canadian Neonatal Network reported that $52 \%$ of infants with birth weight $<1,500 \mathrm{~g}$ have a mean arterial BP less than their GA on the first day after birth, and thus may be diagnosed with and treated for 'hypotension' [27].

It is uncertain whether hypotension (however defined) results in adverse clinical outcomes, including adverse short-term outcomes (increased incidence of intraventricular haemorrhage) [28] and adverse long-term neurode- 
velopmental outcomes [29-31]. Furthermore, it is unclear whether intervention to treat hypotension results in improved outcomes. Dopamine, the most commonly used agent, has not been shown to improve clinical outcomes.

\section{Evaluating Systemic Perfusion}

Currently, there is no validated clinical scoring system to diagnose shock - or failure of systemic perfusion - in preterm infants, and assessment of the adequacy of endorgan blood flow is mostly subjective. Clinical evaluation includes assessment of capillary refill time, skin colour, temperature and urine output. Capillary refill time values exist for term newborns [32], but there are limited data available for preterm infants $[33,34]$. Although there is a significant relationship between cardiac index (cardiac output/body surface area) and capillary refill time in preterm babies, there appears to be only a weak association between capillary refill and systemic blood flow [33]. We previously identified a weak relationship between capillary refill values and simultaneously obtained echocardiographic measures of superior vena cava (SVC) flow [35]. Though the glomerular filtration rate rises rapidly after birth, urine output is low and variable in the first $24 \mathrm{~h}$, the period when preterm infants are most commonly treated for hypotension, making it a less useful measurement. Indeed, none of these parameters in isolation is specific for identifying poor perfusion. Whilst the positive predictive value of each of these individual measures for identifying poor perfusion is low, it appears that using a combination of signs may allow identification of patients at higher risk of poor outcomes [11].

Biochemical methods used to evaluate the adequacy of end-organ perfusion include the measurement of serum levels of lactate, an acid produced during anaerobic metabolism. Lactate values have been analysed in a number of clinical situations in the preterm infant, including the need for erythrocyte transfusion, sepsis [36] and necrotising enterocolitis [37]. Elevated or increasing values obtained on the first day of postnatal life are associated with increased mortality in preterm and term newborns [38, 39]. A single lactate value $>5.6 \mathrm{mmol} / \mathrm{l}$ obtained on the first day was associated with an increased risk of adverse outcome, defined as death or severe intraventricular haemorrhage [40]. In contrast, Wardle [41] found no difference in lactate levels between normotensive and hypotensive preterm infants. We identified a weak negative correlation between lactate values and SVC flow in a cohort of very low birth weight infants. Combined lactate values of $>4 \mathrm{mmol} / \mathrm{l}$ and prolonged capillary refill times $>4 \mathrm{~s}$ resulted in a positive predictive value of $80 \%$ and a negative predictive value of $88 \%$ for identifying low SVC flow, highlighting the value of combining clinical and biochemical parameters [42] in the assessment of the adequacy of end-organ blood flow.

Current standard approaches to the evaluation and treatment of transitional circulatory problems in the preterm infant are not evidence based. We recently established the HIP (Hypotension in Preterm Infants) Consortium, comprising neonatologists, scientists, pharmacologists and industry partners. The Seventh Framework of the European Union funds the consortium. HIP is designed to evaluate two strategies in a randomised controlled trial, and define the efficacy of the most commonly used inotropic medication, dopamine (EudraCT No. 2010-023988-17; Clinical Trial Registration No.: clinical trials.gov NCT01482559).

We will use a combination of clinical and biochemical parameters to determine adequacy of perfusion in the hypotensive preterm infant. We also plan objectively to assess the adequacy of end-organ perfusion with functional echocardiography, near-infrared spectroscopy and electroencephalography (EEG). These methods will be applied in subgroups of infants in order to elucidate causal pathways for any clinical effects that we demonstrate.

\section{Selection of Subjects}

\section{Inclusion Criteria}

- GA at birth from 23 weeks to $<28$ completed weeks, i.e. up to and including 27 weeks and 6 days

- Postnatal age within $72 \mathrm{~h}$ of birth and an indwelling arterial line, suitably calibrated and zeroed, to monitor $\mathrm{BP}$ with the measuring dome at the level of the midaxillary line

- A mean BP $1 \mathrm{~mm} \mathrm{Hg}$ or more below a mean BP value equivalent to the GA in completed weeks, which persists over a 15-min period

- A pre-trial cranial ultrasound scan free from grade IIIIV intraventricular haemorrhage or cystic periventricular leucomalacia

\section{- Written informed consent}

\section{Exclusion Criteria}

- Considered non-viable by attending clinicians

- Life-threatening congenital abnormalities including congenital heart disease (excluding patent ductus arteriosus) and chromosomal abnormalities; infants 
Fig. 1. Treatment algorithm for the management of low BP in extremely preterm infants during the first $72 \mathrm{~h}$ of life.

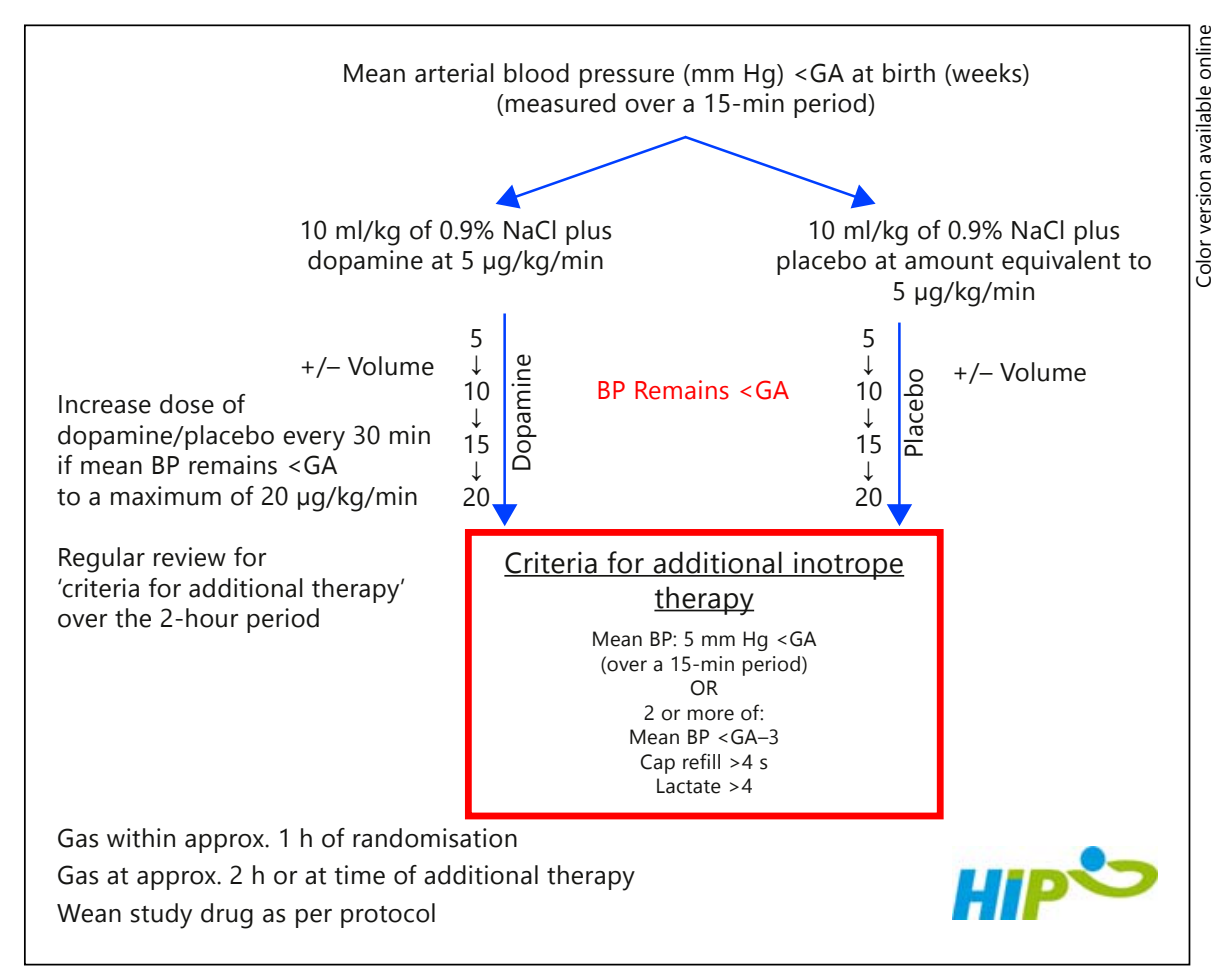

known to require surgical treatment, e.g. congenital diaphragmatic hernia, tracheo-esophageal fistula, omphalocele, gastroschisis; hydrops fetalis

- Cranial ultrasound abnormality grade III intraventricular haemorrhage or more prior to enrolment

The primary objective is to determine whether, in infants of $<28$ completed weeks of gestation and $<72 \mathrm{~h}$ after birth, an observational approach to the management of low mean BP compared to using dopamine as a pressor agent at a predetermined threshold improves:

(1)Survival without significant brain injury at 36 weeks' postmenstrual age. Severe brain injury is defined as moderate or severe ventricular dilatation (determined by a combination of increased ventricular index $>12$ $\mathrm{mm}$, thalamo-occipital distance and anterior horn index), intracerebral haemorrhagic lesions, porencephalic cyst, or cystic periventricular leucomalacia on cranial ultrasound at or nearest 36 weeks.

(2)Survival without neurodevelopmental disability at 2 years of age, corrected for prematurity; neurodevelopmental disability is defined as cerebral palsy with a Gross Motor Function Classification System of 3 or more, or a core on the Bayley Scales of Infant Development (version III) below 80 on either the cognitive or language scale, hearing loss requiring amplification or visual loss 20/200
Secondary objectives will determine whether an observational approach to the management of hypotension compared to using dopamine at a predetermined threshold affects:

(1)All-cause mortality at 36 weeks' postmenstrual age

(3)The incidence of severe brain injury (as defined above) detected on serial cranial ultrasound examinations

(4)The number of adverse effects attributable to treatment

(5)The prevalence of individual impairments at 2 years

(6)Developmental and behavioural scores at 2 years

\section{Study Design}

This is a large, pragmatic, multicentre, international, randomised trial of two different strategies for the management of hypotension in babies born $<28$ completed weeks of gestation. Eight hundred and thirty newborn babies will be enrolled in the first $72 \mathrm{~h}$ of life. Standard management with dopamine will be compared to a restricted treatment approach, delaying intervention until clinical assessment indicates reduced perfusion. The two interventions therefore are (1) saline bolus followed by dopamine compared to (2) saline bolus followed by placebo. Both are accompanied by careful observation and rescue treatment with an alternative inotrope if clinical signs of poor perfusion develop using pre-set criteria (fig. 1). Both 
approaches are commonly used in the management of hypotension in the preterm infant.

The trial design strives for simplicity, efficiency and generalisability. Study treatment, dopamine at $5 \mu \mathrm{g} / \mathrm{kg} /$ min or an equivalent volume of placebo, will be commenced when the mean arterial $\mathrm{BP}$, measured from an indwelling catheter, falls to $\geq 1 \mathrm{~mm} \mathrm{Hg}$ below a threshold value equivalent to the birth gestation in completed weeks (i.e. mean arterial BP $\leq 23 \mathrm{~mm} \mathrm{Hg}$ in an infant born at 24 completed weeks of gestation). Study medication will be increased in a stepwise fashion until the BP exceeds the treatment threshold, up to a maximum of $20 \mu \mathrm{g} / \mathrm{kg} / \mathrm{min}$ of dopamine or equivalent volume of placebo. A combination of BP values and clinical signs/biochemical findings will be used to determine whether an infant should subsequently receive rescue treatment. There are two criteria for rescue treatment, either a mean $\mathrm{BP}$ value $>5 \mathrm{~mm}$ $\mathrm{Hg}$ below threshold or a combination of two or more signs reflecting poor perfusion, namely a mean $\mathrm{BP}$ value $3 \mathrm{~mm} \mathrm{Hg}$ below threshold, lactate $>4 \mathrm{mmol} / \mathrm{l}$ or a capillary refill time $>4 \mathrm{~s}$. We will assess the composite co-primary outcome at 36 weeks' postmenstrual age as set out above. These outcome measures are either objective (death) or adjudicated in a standardised manner by cranial ultrasound findings. Locally based, centrally trained and accredited evaluators masked to group allocation will assess the co-primary outcome of survival without neurodevelopmental disability at 2 years of age, corrected for weeks of prematurity.

\section{Additional Tests to Evaluate End-Organ Perfusion}

Subgroups of babies enrolled in the HIP trial will be assessed using:

- Functional echocardiography to evaluate cardiac output (right ventricular output, left ventricular output and SVC) and cardiac function $[43,44]$

- Near-infrared spectroscopy to assess cerebral oxygenation $[41,45,46]$

- Continuous multi-channel EEG to determine effects of mean BP on cerebral electrical activity $[10,47]$

\section{Statistics}

After 28 weeks of gestation, the frequency of hypotension requiring treatment and of the adverse outcomes described decrease sharply. We therefore intend to enrol infants up to 27 weeks and 6 days of gestation in order to maximise enrolment without adversely affecting study power. Current mortality for infants $<28$ weeks' gestation is about $20 \%$. Among survivors, approximately $30 \%$ have a cerebral ultrasound abnormality, $9 \%$ of which are intra-

Management of Hypotension In Preterm Infants ventricular haemorrhage without ventricular dilatation, leaving $21 \%$ of survivors with the primary outcome. Therefore, the calculated incidence of the composite primary outcome, death or serious brain injury, will be approximately $37 \%$ in the control group. Recent studies including groups of infants up to 27 weeks and 6 days of gestation have shown an incidence of significant developmental delay or neurological abnormality of approximately $32 \%$ among survivors, to give an event rate for the second co-primary outcome of $46 \%$. Assuming patients with cardiovascular instability may be at greater risk of adverse outcome, the sample size was initially calculated on the basis that the proportion of controls experiencing the primary outcome was $50 \%$. A requirement for a sample size of 385 infants in each group was based on a twotailed type 1 error rate of 0.05 , a statistical power of $80 \%$ and a reduction to $40 \%$ in the intervention group. Assuming a loss-to-follow-up rate of no more than $10 \%$, enrolment of 830 subjects will be required. All data analyses will be performed according to the intention-to-treat principle. We feel that this approach is reasonable, given that at present the state of knowledge is such that we neither know the appropriate indications for treatment nor the appropriate interventions to use. Our study will be the first to determine if there is a significant difference between the current standard approach involving dopamine and a more observational approach, with later addition of an inotrope if the clinical criteria are met.

\section{Ethical and Regulatory Requirements}

An ethics advisory group has been established to ensure all participants meet the appropriate ethical requirements. This group comprises a neonatologist, an independent obstetrician, a lawyer, a professor of clinical ethics and a parent advocate. They will review the overall consent process for the trial and will review the parent information sheets and consent forms to ensure they comply with Good Clinical Practice.

An independent data safety monitoring board will conduct reviews of patient safety reports every 6 months, as well as formal interim analyses when approximately $25 \%$, $50 \%$ and $75 \%$ of the anticipated outcome data is available. A sequential analysis of the 36-week composite primary endpoint using the Haybittle-Peto method will be made with $\mathrm{p}<0.001$ required at each analysis for the data safety monitoring board to recommend to the trial steering committee and the project coordination committee whether the trial should be stopped on the basis of efficacy. 
The funding obtained to perform this trial was obtained through the Seventh Framework Programme of the European Commission, under the adaptation of offpatent medicines call. The ultimate goal of this initiative is to obtain paediatric use marketing authorisation for drugs not currently licensed for use in newborn infants, notably dopamine in the management of hypotension in the preterm infant. The consortium have submitted and obtained a Paediatric Investigational Plan (PIP) from the European Medicines Agency to perform this clinical trial (EMEA-001105-PIP01-10) [48].

\section{Conclusion}

There is substantial uncertainty regarding two important questions in the care of the extremely preterm baby: when should we treat hypotension and which strategy should we use? The proposed study will provide evidence to determine the former, and in using the most commonly used inotropic agent it will provide a baseline against which to evaluate other agents.

The goal in modern neonatal care of extremely preterm infants is to avoid death and also to reduce later neu- rological impairment. In contrast to other studies in this area, most of which have simply examined effects on BP, we have sufficient power to provide a robust estimate of the benefit of treatment on clinically important endpoints: survival, brain injury and developmental impairments in a very high risk group.

\section{Acknowledgements}

The HIP Trial is funded by the European Commission within the 7th Framework Programme. Neil Marlow receives a proportion of funding from the Department of Health's NIHR Biomedical Research Centres funding scheme at UCLH/UCL.

We would like to thank the members of the Data Monitoring Committee (Prof. Henry Halliday, Dr. Al Ozonoff and Prof. JeanChristophe Mercier) and members of the Scientific Advisory Board (Neil Finer, Martin Kluckow and Michael Weindling) for their input to date.

We would like to acknowledge the administrative support provided by Ms. Tanja Oster, Ms. Ita Herlihy and Ms. Niamh O Shea.

\section{Disclosure Statement}

None to declare.

\section{References}

1 Dempsey EM, Barrington KJ: Diagnostic criteria and therapeutic interventions for the hypotensive very low birth weight infant. J Perinatol 2006;26:677-681.

$\checkmark 2$ Laughon $\mathrm{M}$, et al: Factors associated with treatment for hypotension in extremely low gestational age newborns during the first postnatal week. Pediatrics 2007;119:273-280.

-3 Dempsey EM, Barrington KJ: Treating hypotension in the preterm infant: when and with what: a critical and systematic review. J Perinatol 2007;27:469-478.

4 Osborn DA, Evans N: Early volume expansion for prevention of morbidity and mortality in very preterm infants. Cochrane Database Syst Rev 2004;2:CD002055.

5 Subhedar NV, Shaw NJ: Dopamine versus dobutamine for hypotensive preterm infants. Cochrane Database Syst Rev 2003;3:CD001242.

6 Ibrahim H, Sinha IP, Subhedar NV: Corticosteroids for treating hypotension in preterm infants. Cochrane Database Syst Rev 2011; 12:CD003662.

7 Kluckow M, Evans N: Relationship between blood pressure and cardiac output in preterm infants requiring mechanical ventilation. J Pediatr 1996;129:506-512.

8 Pladys P, et al: Left ventricle output and mean arterial blood pressure in preterm infants during the 1st day of life. Eur J Pediatr 1999; 15 Zhang J, et al: Mechanisms of blood pressure 158:817-824.

-9 Groves AM, et al: Relationship between blood pressure and blood flow in newborn preterm infants. Arch Dis Child Fetal Neonatal Ed 2008;93:F29-F32.

10 Victor S, et al: The relationship between cardiac output, cerebral electrical activity, cerebral fractional oxygen extraction and peripheral blood flow in premature newborn infants. Pediatr Res 2006;60:456460.

11 Dempsey EM, Al Hazzani F, Barrington KJ: Permissive hypotension in the extremely low birthweight infant with signs of good perfusion. Arch Dis Child Fetal Neonatal Ed 2009; 94:F241-F244.

12 Synnes AR, et al: Variations in intraventricular hemorrhage incidence rates among Canadian neonatal intensive care units. J Pediatr 2001;138:525-531.

13 Goldberg RN, et al: The association of rapid volume expansion and intraventricular hemorrhage in the preterm infant. J Pediatr 1980; 96:1060-1063.

14 Filippi L, et al: Dopamine versus dobutamine in very low birthweight infants: endocrine effects. Arch Dis Child Fetal Neonatal Ed 2007; 92:F367-F371. increase induced by dopamine in hypotensive preterm neonates. Arch Dis Child Fetal Neonatal Ed 1999;81:F99-F104.

16 Osborn D, Evans N, Kluckow M: Randomized trial of dobutamine versus dopamine in preterm infants with low systemic blood flow. J Pediatr 2002;140:183-191.

17 Lee J, Rajadurai VS, Tan KW: Blood pressure standards for very low birthweight infants during the first day of life. Arch Dis Child Fetal Neonatal Ed 1999;81:F168-F170.

18 Spinazzola RM, Harper RG: Blood pressure values in 500- to 750-gram birthweight infants in the first week of life. J Perinatol 1991;11:147.

19 Watkins AM, West CR, Cooke RW: Blood pressure and cerebral haemorrhage and ischaemia in very low birthweight infants. Early Hum Dev 1989;19:103.

20 Versmold HT, et al: Aortic blood pressure during the first 12 hours of life in infants with birth weight 610 to 4,220 grams. Pediatrics 1981;67:607-613.

21 Hegyi T, et al: Blood pressure ranges in premature infants. I. The first hours of life. J Pediatr 1994;124:627-633.

22 Hegyi $\mathrm{T}$, et al: Blood pressure ranges in premature infants: II. The first week of life. Pediatrics 1996;97:336-342. 
23 Bada $\mathrm{H}$, et al: Mean arterial blood pressure changes in premature infants and those at risk for intraventricular hemorrhage. J Pediatr 1990;117:607-614.

24 Development of audit measures and guidelines for good practice in the management of neonatal respiratory distress syndrome. Report of a Joint Working Group of the British Association of Perinatal Medicine and the Research Unit of the Royal College of Physicians. Arch Dis Child 1992;67:1221-1227.

$>25$ Pellicer A, et al: Cardiovascular support for low birth weight infants and cerebral hemodynamics: a randomized, blinded, clinical trial. Pediatrics 2005;115:1501-1512.

26 Cunningham S, et al: Intra-arterial blood pressure reference ranges, death and morbidity in very low birthweight infants during the first seven days of life. Early Hum Dev 1999. 56:151-165.

27 Barrington K, Lee S, Stewart S: Differing blood pressure thresholds in preterm infants, effects on frequency of diagnosis of hypotension and intraventricular hemorrhage. PAS Meeting Abstracts 2002;2648.

-28 Miall-Allen VM, De Vries LS, Whitelaw AL: Mean arterial blood pressure and neonatal cerebral lesions. Arch Dis Child 1987;62:10681069.

29 Martens SE, et al: Is hypotension a major risk factor for neurological morbidity at term age in very preterm infants? Early Hum Dev 2003; 75:79-89.

30 Murphy D, et al: Case-control study of antenatal and intrapartum risk factors for cerebral palsy in very preterm singleton babies. Lancet 1995;346:1449-1454.
31 O'Shea T, et al: Survival and developmental disability in infants with birth weights of 501 to 800 grams, born between 1979 and 1994 . Pediatrics 1997;100:982-986.

32 Raju NV, et al: Capillary refill time in the hands and feet of normal newborn infants. Clin Pediatr (Phila) 1999;38:139-144.

33 Wodey E, et al: Capillary refilling time and hemodynamics in neonates: a Doppler echocar diographic evaluation. Crit Care Med 1998; 26:1437-1440.

34 Osborn DA, Evans N, Kluckow M: Clinical detection of low upper body blood flow in very premature infants using blood pressure, capillary refill time, and central-peripheral temperature difference. Arch Dis Child Fetal Neonatal Ed 2004;89:F168-F173.

35 Miletin J, Pichova K, Dempsey E: Bedside detection of low systemic flow in the very low birth weight infant on day 1 of life. Eur J Pediatr 2009;168:809-813.

36 Fitzgerald MJ, Goto M: Early metabolic effects of sepsis in the preterm infant: lactic acidosis and increased glucose requirement. J Pediatr 1992;121:951.

37 Abubacker M, Yoxall CW, Lamont G: Perioperative blood lactate concentrations in preterm babies with necrotising enterocolitis. Eur J Pediatr Surg 2003;13:35-39.

38 Groenendaal F, et al: Early arterial lactate and prediction of outcome in preterm neonates admitted to a neonatal intensive care unit. Biol Neonate 2003;83:171-176.
39 Deshpande SA, Platt MP: Association between blood lactate and acid-base status and mortality in ventilated babies. Arch Dis Child Fetal Neonatal Ed 1997;76:F15-F20.

40 Nadeem M, Clarke A, Dempsey E: Day 1 serum lactate values in preterm infants less than 32 weeks gestation. Eur J Pediatr 2010;169: 667-670.

41 Wardle SP, Yoxall CW, Weindling AM: Peripheral oxygenation in hypotensive preterm babies. Pediatr Res 1999;45:343-349.

42 Miletin J, Dempsey EM: Low superior vena cava flow on day 1 and adverse outcome in the very low birthweight infant. Arch Dis Child Fetal Neonatal Ed 2008;93:F368-F371.

43 Evans N, Iyer P: Incompetence of the foramen ovale in preterm infants supported by mechanical ventilation. J Pediatr 1994;125:786792.

44 Evans N, Iyer P: Assessment of ductus arteriosus shunt in preterm infants supported by mechanical ventilation: effect of interatrial shunting. J Pediatr 1994;125:778-785.

45 Naulaers G, et al: Cerebral tissue oxygenation index in very premature infants. Arch Dis Child Fetal Neonatal Ed 2002;87:F189-F192.

46 Nicklin SE, et al: The light still shines, but not that brightly? The current status of perinatal near infrared spectroscopy. Arch Dis Child Fetal Neonatal Ed 2003;88:F263.

47 West CR, et al: Early low cardiac output is associated with compromised electroencephalographic activity in very preterm infants. $\mathrm{Pe}$ diatr Res 2006;59:610-615.

48 Dempsey EM, Connolly K: Who are the PDCO? Eur J Pediatr 2013, Epub ahead of print. 